\title{
Tendências religiosas no cenário brasileiro contemporâneo
}

Religious trends in the Brazilian contemporary

\author{
Palestra do Pe. João Batista Libanio* \\ Aula inaugural do Programa Pós Graduação Ciências da Religião \\ PUC Minas - 18 de abril $2012^{1}$
}

\section{Abertura}

Mauro Passos - Boa noite a todos! Nós já conhecemos o Pe. João Batista Libanio, então eu vou simplificar a apresentação e de início destacar o livro publicado pelas Edições Paulinas, intitulado "Teologia para viver com sentido", em homenagem ao 80 anos de vida do Libanio. Esta obra elenca as obras e as atividades do teólogo. Desse modo, ao mostrar o livro eu faço a apresentação visual da grande trajetória do Libanio. E passo a ele a palavra, pois estamos aqui para ouvi-lo. Obrigado, Libanio.

\footnotetext{
Comunicação recebida em 12 de julho de 2012 e aprovada em 09 de agosto de 2012.

* Doutor em Teologia (Gregoria-Roma) e professor da FAJE (Faculdade Jesuíta de Filosofia e Teologia). País de origem: Brasil. E-mail: secteologia@faculdadejesuita.edu.br

${ }^{1}$ Transcrição da Palestra de João Batista Libanio, revista pelo autor, realizada por Patrícia Simone do Prado, mestranda do Programa de Pós-graduação em Ciências da Religião da PUC Minas.
} 


\section{Palestra}

Libanio - Então minha juventude, boa noite a todos. Muito me alegra falar para os discentes do curso de Ciências das Religiões da PUC Minas. A Teologia e as Ciências da Religião de vez em quando se estranham. Na busca de promover o diálogo, encontramo-nos de maneira fraternal e sororal.

O tema de hoje soa: Tendências religiosas na atual situação contemporânea. Tendências religiosas no cenário brasileiro contemporâneo.

A presente abordagem privilegia a perspectiva interdisciplinar, ou seja, toca várias ciências, por vezes, distantes de meu cotidiano. Aqui reside a vantagem de se tratar de abordagem interdisciplinar. Em celebração em honra de Dom Paulo Evaristo Arns, um dos oradores de outra ciência que não a teologia, ironicamente comentou: "Dos assuntos que conhecemos, falamos com muito cuidado, com vírgula, ponto e vírgula. Mas dos assuntos que não entendemos, falamos com segurança enorme. Então vou falar com segurança enorme." E completou: "eu vou falar de Teologia”. Parafraseando esse orador, de cujo nome não me lembro, mesclarei diferentes discursos. Como falar sobre as tendências religiosas, sem se considerarem aspectos epistemológicos variados? Isso porque não se devem abordar as tendências religiosas somente pelo viés teológico.

Começo com distinção simples, porém, necessária e oportuna. Proponho uma espécie de purificação semântica da palavra/adjetivo "religioso", "religiosa". Tal expressão condensa sutil ambiguidade e comporta vários sentidos. A interpretação da imprensa e das pessoas não especializadas no universo das ciências da religião e da teologia confunde e dificulta a devida compreensão. Com o intuito de esclarecer os equívocos instaurados, distingo três conceitos fundamentais. Atenção: distingo, não os separo?! "Distinção" implica a percepção

${ }^{2}$ Importa filosoficamente perceber a diferença entre "distinção" e "separação". 
de diferentes aspectos presentes na mesma realidade, de modo global, em conjunto, a configurar unidade. Entretanto se percebem aspectos e facetas bem diferentes a tecer a realidade. Daí a distinção entre facetas a se entrelaçarem, interconectarem. Os meus alunos já conhecem a distinção antiga que faço entre "religião, "religiosidade" e "fé” (LIBANIO, 2011, p. 87-110).

Alguns dizem: "estou em crise de fé". Mas na verdade não se está em nenhuma crise de fé, mas sim, em crise de religião. Outros, por sua vez, perderam a religiosidade e podem estar repletos de religião. Ou ainda se tem muita fé e nenhuma religiosidade. Essa provocação inicial nos possibilita situar a diferença. Para entender tendências religiosas, defrontamo-nos com o adjetivo "religiosas". Ele é adjetivo de que substantivo? Essa é a pergunta. Tratarei de três substantivos em vez dos adjetivos. Quando falo de "religião", considero o aspecto de instituição. Nesse sentido, religião supõe a organização do tempo, do espaço, dos ritos, das sagas, das lendas, das doutrinas, da hora3 ${ }^{3}$ Alguém pode ser excelente membro de determinada religião e não ter fé nenhuma. Assim diante das prescrições da religião doutrinais ou outras, uma pessoa pode ter dificuldade de aceitar. Não necessariamente se trata de um problema de fé, é possível simplesmente não aceitar a injunção institucional.

Outro exemplo: a Mulher pode ser padre na Igreja Católica? Não, responde a Instituição. Alguém que não aceita tal decisão, entra em choque com a Instituição, mas não necessariamente com a Revelação de Deus. Questão antes institucional que de fé, ao menos para a consciência de muitos fieis.

A tendência da religião, enquanto instituição, tem especificidade própria. A análise visa a ver a relação das pessoas com a Instituição como tal.

Por outro lado, quando falo de religiosidade, refiro-me à dimensão de experiência subjetiva. Por exemplo: diante de cena bonita, de celebração tocante,

\footnotetext{
${ }^{3}$ Por exemplo, a missa se inicia às 7 horas da manhã e será presidida pelo Monsenhor Raimundo. Ele chega às 7 e cumpre sua função. Tal monsenhor pode até não ter fé alguma e mesmo assim o evento acontece. Isso porque a religião organiza e possibilita a celebração.
} 
comovo-me até as lágrimas. Subo lá ao alto da Serra do Cipó e ponho-me a contemplar o cair da tarde a me falar de Deus. Eu acredito em Deus? Não sei. Mas senti-me tocado "religiosamente", no sentido de religiosidade. São Paulo fala de "suspiros inenarráveis" que podem remontar simplesmente da parte afetiva religiosa, independentemente das determinações institucionais, com as quais se está ou não de acordo. Isso não entra em questão. Tenho devoção a São Judas Tadeu, a Santa Edwiges. Por quê? Por imposição da religião? Não sei. Só sei que eu tenho tal devoção a São Judas Tadeu, a Santa Edwiges. Essas práticas, experiências e vivências religiosas me unem a Deus, a um Transcendente, a um Mistério Vago, a uma Energia suprema? A pessoa não se formula tal pergunta. Permanece no nível da religiosidade.

Certa vez, naquela época do movimento Jesus Revolution, perguntou o repórter à jovenzinha brasileira : quem é para você Jesus? Ah, Jesus é isso, ah Jesus, enche a gente. Suspirava mais que falava. Que fé expressava? Nenhuma. Que religião? Nenhuma. Era simplesmente piedosa em seus suspiros e gemidos. Pura religiosidade. Achava bonito ver Jesus jovem com aquela cruz nas costas. Ela trajava uma blusa com a inscrição: “Jesus I love you!” Isso traduz religiosidade.

A fé se situa em outro departamento. Irei falar apenas da fé cristã. A restrição facilita a abordagem. A fé cristã supõe a existência da revelação divina. Existe a Palavra de Deus que acolho enquanto Palavra transcendente e me interpela. Vejamos o Evangelho de Marcos (Mc 1, 15): “o tempo chegou à plenitude; o Reino de Deus está próximo; convertei-vos; crede no Evangelho”. Supõe a presença do Reino que interpela. Acolhido, implica conversão e compromisso. Portanto, existe uma palavra de Deus a me questionar, a me exigir mudança de vida, como os profetas pregavam: “convertei-vos, convertei povo judeu; cuidado, não façais isso; fazei penitência; jejuai”. A conversão e a mudança de vida expressam apelo da fé e não da religião. Comprometei-vos com Javé, com o verdadeiro Deus. João Batista, a voz clamante no deserto, dizia: “Convertei-vos”! João Batista não fundou religião nenhuma, sequer era sacerdote. Leonardo Boff diz 
de maneira provocante: Jesus não foi sacerdote, foi leigo”. Curioso: Jesus foi mesmo leigo! Jesus dá o exemplo de fé quimicamente pura, o único a tê-la vivido: morreu fora da religião e sem religiosidade. Só na fé. Por que ele morreu fora da religião? Porque o sumo sacerdote, espécie de Papa daquela época, expulsou-o da religião judaica, ao rasgar a veste e dizer: blasfemou! Blasfemou, está excomungado! E Jesus, por assim dizer, ficou fora da religião judaica. Portanto, sem nenhuma religião. E a religiosidade? Na cruz, não sentia nenhuma consolação, prazer, gozo. Não disse: ah, oh doce cruz, que prazer imenso. Pelo contrário, sentia dor terrível, câimbra violenta, hemorragia enorme. Nenhuma religiosidade. Que religiosidade aguenta tal sofrimento? Não exclamara na agonia do Horto: Pai afasta de mim esse cálice? Suou sangue. Que religiosidade é essa? Ele não é masoquista! Mas a última palavra antes de morrer foi de pura fé. Pai, em tuas mãos entrego o meu espírito. Pai em tuas mãos eu me entrego. Isso é pura fé. Claro, é Jesus. O Único que pode viver a fé quimicamente pura e viveu-a naquele instante final. Durante a vida, praticou a religião, foi à sinagoga, foi ao templo. Então, eu posso viver a religião, a religiosidade e a fé em momentos bem distintos. Mas normalmente, sociologicamente vivemos a fé cristã, dispomos de expressões religiosas da fé cristã e temos uma religião a nos ajudar a organizar a nossa fé cristã. Daí se percebe como as três dimensões se intercalam. Na prática, no concreto, a religião católica, que é nossa religião, ou a religião evangélica ou outra religião qualquer: que ela quer? Favorecer a religiosidade das pessoas. Para isso, usa de recursos humanos que toquem a subjetividade religiosa: toca órgão com música bonita, põe roupa vistosa, orna o altar. Para quê? Para as pessoas sentiremse bem! 4

Agora cabe a pergunta: qual é a atual conjuntura a se analisar, à luz dessa distinção estabelecida? O futuro da religião católica enquanto religião é um; o

\footnotetext{
${ }^{4}$ Imaginemos uma igreja com cadeiras bonitas para as pessoas se sentarem e ficarem quietas. Põe-se música de fundo a compor o ambiente tomado por perfumes franceses. Tudo fica ótimo! Depois se celebra a Eucaristia na qual se acredita - fé - mas uma eucaristia organizada pela religião e a nutrir a religiosidade das pessoas. E as três dimensões seguem intercaladas.
} 
futuro da religiosidade não é o mesmo; e o futuro da fé também não é o mesmo. Em outras palavras: que tendências existem nessas três realidades?

Tendência significa que se sai de A e se vai para Z. Não se diz, porém, em que altura da tendência se está. O leitor, ao analisar a realidade que deseja, localiza conforme os dados disponíveis. Não se trata de defender uma tese. Implica a percepção do movimento da história. Será correta ou não, conforme se perceba bem ou não, o movimento. Não se toma posição, nem ela é criticada, nem avaliada, mas constatada como o caminhar da história. Perceber a história não contraria nenhuma doutrina. Conhecemos a tendência pelos sinais que nos indicam para onde se vai. Capto as tendências e estabeleço a distinção: religião, religiosidade e fé.

Mas antes, tracemos um quadro geral para situar as tendências. Primeiro: Tenho a impressão de que o processo gigantesco de mercantilização de todas as coisas afeta grandemente as três, mas mais a religião e a religiosidade. Encontra-se em curso a tremenda tendência de se mercantilizar tudo. Em reunião em que participei recentemente para discutir sobre Rio + 20, Ivo Lesbaupin explicou-nos o projeto Draft zero. Boff, ironicamente, comentou: É zero mesmo quando fala da economia verde. A economia verde é uma maneira que eles estão tentando de mercantilizar o aspecto ecológico da natureza. Eles querem pagar, por exemplo, os índios porque eles protegem um córrego, uma matazinha. Parece algo humano, mas, no fundo, está-se a mercantilizar um bem que não é mercantilizável: água, mata.

Os bens necessários e fundamentais para a existência tornam-se mercantilizáveis. Tal fenômeno atinge o amor, as relações pessoais e interpessoais. Cada vez mais as relações pessoais estão sendo mercantilizadas. Não é de estranhar que tal movimento afete altamente a religião e mais ainda a religiosidade e indiretamente a fé.

Uma segunda tendência: a fragmentação - um dos elementos fundamentais da pós-modernidade. Fragmentação de quê? Fragmentação sob diversos aspectos, 
a principiar pela pessoa humana. Alguém faz uma ação e se pergunta: Será que fui eu que fiz ou foi o id? Não. Acho que foi o superego que me levou a fazer isso. Não. Foi o id. Não. Foi o ego. Aí já não sabe quem fez. Quem vai para a cadeia: o ego, o id ou superego?

A análise freudiana tem a capacidade de entrar dentro de nós e nos dá a sensação de que todas as coisas são fragmentadas, quebradas. Lá dentro, a coisa mais profunda é fragmentada que somos nós mesmos. Meu eu é fragmentado. A minha identidade não é mais identidade. Talvez uma das crises fortes que tenhamos no momento, pela fragmentação, seja a da identidade. São todas identidades! Você é médico? Não, eu sou especialista no nervo tal. Você é dentista? Não, eu cuido só da cárie do molar inferior direito. Quer dizer, quanto mais nos especializamos, as profissões e as vocações padecem da mesma fragmentação. E que acontece com a religião fragmentada? Torna-se congérie enorme de ritos, de doutrinas, de práticas. Que faz o comércio? Toma os fragmentos e mercantiliza-os. Cria-se relação profunda entre a fragmentação e a mercantilização.

Uma terceira tendência conduz-nos à posição ambígua em face da instituição. Estamos a experimentar a respeito dos cursos que caem sob a égide da CAPES. Percebemos grande rejeição da instituição. Não é verdade? Vejam o que se fala dos deputados, o que os jornais noticiam sobre o Senado. Li em breve noticiário da Globo que os senadores, os deputados do Brasil se incluem entre os mais caros do mundo. Que quer dizer isso? Que a instituição política está desprestigiada. E a corrupção do judiciário? Envergonha-o. Quantidade de juízes, desembargadores envolvidos em corrupção. Ironiza-se sobre o perigo do "Cachoeira" que está a "molhar" todas as coisas (5).

Outro sinal do desprestígio da Instituição aparece na movimentação de protestos no meio jovem contra o sistema atual: "los indignados de Madrid" os “Occupy Wall Street”, as arruaças nas periferias de Londres, Paris.

\footnotetext{
${ }^{5}$ Alusão ao processo que se moveu contra o bicheiro Carlos Cachoeira que envolveu muitos políticos em jogadas escusas.
} 
Tal fenômeno afeta também a religiosidade, já que ela se pratica no interior de instituições. O mesmo vale, a seu modo, da fé, que se vive em instituições.

Paradoxalmente, ao lado do desprestígio das instituições, assistimos a seu enrijecimento. Inclusive observo na própria Faculdade em que leciono. Antes estávamos no Rio e viemos para fundar o que hoje chamamos de FAJE para ter liberdade de organização e leveza institucional. Vivemos uma lua de mel vários anos. Cada aluno tinha um orientador-professor; substituíramos o sistema de notas por conceitos menos matemáticos. Relativizaram-se os exames de modo que a avaliação se fazia de maneira continuada e diferenciada e outras coisas mais. Pouco a pouco, e sobretudo depois da oficialização dos cursos, o aspecto institucional voltou a pesar sob as exigências da CAPES, do currículo Lattes e quejandos. A revista necessitou enquadrar-se em formalidades que nem sempre conotam o valor interno dos artigos. Sofremos de certa rigidez institucional com a política do MEC, da CAPES.

Por que existe tal endurecimento da instituição? Porque vivemos numa cultura que valoriza a eficiência, a razão instrumental. O filósofo canadense Charles Taylor define, de maneira clara, a razão instrumental. Ela estabelece um objetivo, organiza os meios de maneira competente, eficiente, com baixos custos e altos benefícios. O império dessa razão explica muito do que está a acontecer no mundo de hoje. À guisa de exemplo: estabelece-se o objetivo de elevar a própria revista ao grau Qualis A. Exige do redator que seja competente, eficiente e obtenha tal meta com o menor gasto e o maior benefício. Não pode gastar demais para que a Faculdade não vá à falência. Portanto, baixos custos, altos benefícios.

É essa razão que triunfa hoje. Não é nem a lógica, nem a afetiva, nem a interrelacional, nem a abstrata, mas a instrumental. Ela está a invadir o mundo da religiosidade. Organiza-a de maneira competente e eficiente para que se consiga dinheiro. Se, por exemplo, sei que a devoção a São Judas Tadeu me dá muito dinheiro, construo grande igreja em honra dele. Mas se o santo não traz dinheiro, 
ergo uma capelinha. Eis a razão instrumental: inteligente, competente, eficiente, lucrativa. Ela está a entrar em todos os lugares. Basta ser perspicaz para percebê-lo e não ser ingênuo.

Outro fator está a mudar a religião, a religiosidade e a prática da fé: o predomínio crescente das relações virtuais sobre as relações reais. Profunda transformação por que está a passar a atual cultura. A editora Vozes publicou livro interessante sobre esse fenômeno: STORCH, Lea Waidergorn; COZAC, João Ricardo. Relações virtuais: o lado humano da comunicação eletrônica. Petrópolis: Vozes, 1995.

Os autores são um homem e uma mulher que vêm da psicologia e da comunicação que juntos fizeram a pesquisa. Com licença das pessoas, gravaram, transcreveram e analisaram conversas virtuais de vários tipos humanos.

Algumas coisas me chamaram a atenção. O mundo virtual possibilita as pessoas viverem esquizofrenia virtual. Vejam este caso. Um adolescente entra no MSN sem webcam e assume a figura de um adulto. Como não se vê a pessoa, ninguém poderia imaginar que era ficção. Apresenta-se como adulto e então começa a paquerar mulheres casadas para conhecer-lhes a vida íntima, sexual por pura curiosidade. Elas imaginando que conversavam com adulto, abriam-se e revelavam intimidades. Isso é o mundo de hoje.

Outro exemplo: um jovem se dá dois nomes fictícios: um masculino e outro feminino. Era ao mesmo tempo rapaz e moça. E assim estabelecia relações ora hetero, ora homossexuais, passando de uma para a outra com a maior semcerimônia. O que passa na cabeça de um adolescente assim deve ser uma loucura. Ora, o mundo virtual está a afetar altamente a fé, a religião e a religiosidade.

Mais do que os católicos, os evangélicos neopentecostais, como o pastor Edir Macedo, exploram tanto a razão instrumental como a comunicação eletrônica. No mundo virtual, cria-se a imagem que se quer, estabelece as relações mais díspares 
possíveis! A religião se transforma quase numa empresa, a religiosidade em mercadoria e os fieis em fregueses. $\mathrm{E}$ a fé? Não tem importância a não ser enquanto ela sustenta a religiosidade ou a religião. Como tal, ela critica esses dois universos.

Na década de 6o, jovens do movimento hippy cultivavam o descuido com o exterior: roupa, higiene, cabelos cumpridos, modo de comportar-se. Primavam por chocar a sociedade. Hoje se passa para o outro extremo da estética, do esteticismo. Fala-se da passagem da ética para a estética. Mais: desloca-se o interesse pelos livros para o culto do corpo. As academias suplantam as livrarias. Que significa tal desvio do pensar para o curtir, da práxis para o gozo estético? Em que a valorização da visibilidade, da exterioridade, da beleza, da estética afeta a religião, a religiosidade e a fé?

A Igreja Universal do Reino de Deus tem construído templos maravilhosos. Nós, católicos de Belo Horizonte, estamos a construir uma Catedral projetada por Niemeyer. As liturgias, as alfaias, as vestes, o cenário primam por serem bonitos. Afirma-se a tendência da estetização da religião, da religiosidade, até da fé. Cresce o fascínio pelos escritos dos místicos de beleza inesperada. Antes, quanto mais feio parecia o santo, mais santo se julgava. Há agora, porém, embelezamento dos santos, dos seus escritos.

A pós-modernidade anuncia a morte das grandes narrativas $e \quad o$ surgimento dos pequenos relatos. Conhecemos, décadas atrás, três grandes narrativas que estão a morrer: o socialismo, o evolucionismo teilhardiano e a Divina Providência.

O socialismo imaginava um mundo onde se superariam as desigualdades, onde se realizaria o ideal da comunidade primitiva segundo os Atos dos Apóstolos: Todos os que abraçavam a fé viviam unidos e possuíam tudo em comum; vendiam suas propriedades e seus bens e repartiam o dinheiro entre todos, conforme a necessidade de cada um (Atos dos Apóstolos 2, 44-45). O mundo socialista significava grande e belíssima narrativa. Só que para realizá-la, precisou 
usar da força. Sem o fórceps da repressão, o neném socialista não nasceria. Os seus erros levaram à morte esse mega-relato. Pensa-se em ressuscitá-lo na perspectiva do Eco-Socialismo.

Outra grande narrativa, belíssima, se criou a partir dos pensamentos e escritos de Teilhard de Chardin. Ele vê o processo de evolução na perspectiva da amorização até chegar a sua plenitude no ponto Omega, Deus, Cristo. Imaginava que o progresso tecnológico propiciaria ao ser humano tempo e lazer para conviver solidária e fraternalmente. Aconteceu o contrário. Cada vez se tem menos tempo para a convivência humana.

Os católicos e os cristãos recorriam à grande narrativa da Divina Providência para explicar os acontecimentos ditosos e dolorosos. Assim diante de um mesmo fato que para uns significou felicidade e para outros infelicidade, ambos apelavam para a Divina Providência. Por exemplo. Há um acidente de automóvel. Morre uma pessoa e outra escapa. A respeito da que se salva, a família diz: ah como Deus é bom; a Divina Providência salvou meu filho. O que morreu? Ah! Deus sabe o que faz. Levou-o para Ele. Tal grande relato explicava a vida e a morte.

As religiões viviam de grandes relatos. Então a sua morte afeta-as. A religiosidade, por sua vez, vive bem com as pequenas narrativas. Por isso, ela cresce, enquanto as religiões decrescem.

Portanto, parece equivocado dizer que as religiões estão a aumentar. Antes diminuem. As religiões se comportam como lojas que vendem certos bens. Elas não crescem por elas, mas porque e enquanto as pessoas buscam o que elas oferecem. Ninguém vai a uma loja por ela, mas pelo que quer comprar. Por isso, as lojazinhas estão a falir e os Shoppings a crescer. Quanto mais uma religião se assemelha ao Supermercado, ao Shopping, mais ela aumenta. Não sem razão, Thomas Luckmann usa a metáfora do supermercado para explicar o fenômeno religioso atual [The invisible religion: the problem of religion in modern society. New York: The Macmillan Company, 1972]. Multiplicam-se as lojas por causa da diversidade de 
produtos e desejos dos clientes. As religiões estão a vender expressões religiosas que atraiam as pessoas.

Mais uma tendência: o aumento do pluralismo religioso. Alguém pode dizer: sempre houve pluralismo. Assim a linha de Santo Tomás divergia da de São Boaventura e de outros pensadores de seu tempo. Mas aqui se trata de outra concepção, como bem observou K. Rahner.

O pluralismo de hoje vai mais fundo. Afeta a própria maneira de nós nos pensarmos a nós mesmos. Em vez de nos pensarmos, como simples corpo e alma, a antropologia moderna complexificou tal compreensão. H. Vaz explicita as três dimensões: corpo, alma, espírito na sua quádrupla relação: consigo, com as outras pessoas, com o mundo e com a Transcendência. Em relação a nós, somos consciência - presença de nós mesmos a nós mesmos -, liberdade, autonomia. Já nesse nível surge o pluralismo pelas diferença das presenças a cada um e pelo processo de conscientização que nunca termina. Haja vista o belíssimo poema de Vinicius de Morais Operário em construção, onde se descreve poeticamente o fazer-se crítico da consciência de um operário. Tal tipo de poesia se poderia fazer do engenheiro, do filósofo, do teólogo. Cada um teria percurso diferente. Já aí aparece a pluralidade.

O pluralismo aumenta, ao se estenderem as relações: interpessoal, comunitária, social. O Eu e Tu de Martin Buber contém muito mais complexidade que se imagina. Às relações reais somam-se hoje as virtuais. Abre mundo ilimitado de possibilidades que abarca praticamente todos os países.

A relação com a natureza cria novo e amplíssimo capítulo. A ecologia enriquece tal universo relacional. O último grito do Rio+20 chamou-se economia verde.

A pluralidade na relação com a Transcendência afeta, de modo especial, o nosso tema. Vai desde a transcendência para o cristão, que é a Trindade, até aquela 
que quase se confunde com a imanência. Dois filósofos franceses atuais usam a expressão: Transcendência na imanência. Reivindicam religiosidade, espiritualidade também para os ateus [Comte-Sponville, Andre. O espírito do ateísmo: introdução a uma espiritualidade sem Deus. São Paulo: WMF Martins Fontes, 2007]. A própria imanência é capaz de mostrar-nos a transcendência, mesmo que não se aceite Deus. Temos desejos de infinito, experimentamos a transcendência, como experiência que ultrapassa o aqui agora. Enorme pluralismo.

Diante desse quadro, vejamos para onde caminham a religião, a religiosidade e a fé. As religiões tendem a esfacelar-se, a fragmentar-se. Teremos cada vez mais diferentes religiões. Haja vista a paisagem atual da Religião no Brasil O IBGE está a mostrar-nos nas pesquisas o decréscimo constante de membros da Igreja católica em face do aumento do segmento evangélico em gigantesca pluralidade de denominações. Basta consultarmos essas estatísticas para verificar esse fato evidente até aos olhos de descuidados (6). Crescem também os Semreligião, mas não quer dizer sem religiosidade. Aí aparece claramente a distinção que fizemos no início da palestra. Dos 8\% (censo 2010) Sem-religião, não faltam os que rezam antes de dormir e de manhã cedo. Isso mostra que a religião, como instituição, está a perder a força coercitiva.

Em reação a tal fragmentação e diminuição, ela [a religião] se enrijece, como está a acontecer com a Igreja Católica na esperança de reter, ainda, os últimos marinheiros no navio. Tal postura atrai inseguros minoritários que buscam referências fortes numa pós-modernidade líquida que está a corrê-las: família, valores, instituições respeitáveis no mundo da política, do direito, etc. (Z. Bauman). Assim as religiões rijas e fundamentalistas atraem. Na Igreja Católica, movimentos bem disciplinados seduzem jovens. Porque vivemos numa sociedade sem

\footnotetext{
${ }^{6}$ Para se ter uma ideia, em 1940, o mesmo IBGE constatava um percentual de $95 \%$ de católicos no Brasil. Em 1991, este número pas sou para $83 \%$. Posteriormente, em 2000, na queda mais acentuada, foi para 73,6\%, até chegar, 10 anos depois, nos atuais $64,6 \%$ dos cerca de 190 milhões de brasileiros (Censo 2010). A respeito dos evangélicos: 22,2\% do País está inserido nas crenças das igrejas de missão e pentecostais, dentre outras que pregam o evangelismo. O salto de $6,8 \%$, em relação ao levantamento do ano 2000 , se torna ainda maior se voltarmos ao ano de 1940, quando os evangélicos entraram na pesquisa e apareciam apenas com 2,6\%. Ou seja, em pouco mais de 70 anos, cresceram 20,4\%. Ver IBGE, 2012.
} 
referências. A religião, como instituição, tem ou não futuro? Sim e não. Ela tem futuro enquanto um ponto de referência para os sem referências. Ela ainda protege. Ela não tem futuro diante da autonomia das pessoas, da valorização da subjetividade, da democratização generalizada, enfim do "tudo vale” (anything goes), do "eu sou eu”, do “eu penso assim”. Diante da extrema subjetivização da pós-modernidade, toda instituição sofre detrimento. Pelo caminho da fragmentação e da valorização da subjetividade vai o principal caminho da pósmodernidade.

Ao considerar agora a Igreja Católica, há, sem dúvida, expressiva evasão, claro deslocamento do polo central europeu, romano para as periferias católicas. Comentavam colegas espanhóis que já não se vêem jovens nas igrejas. Se, às vezes, consegue-se reunir multidão deles, como no Encontro com o Papa em Madrid (2011), logo após o evento, eles somem da igreja.

No Terceiro Mundo, porém, com na Índia e, em parte, na América Latina, existe vitalidade da religião católica. Os jesuítas devem ter perto de 500 noviços na Índia. Na Europa, são pouquíssimos. Mesmo no Brasil, o número decresceu significativamente. Esse fenômeno de perda de credibilidade da Religião, como instituição, afeta sobretudo a cultura ocidental que passou pelo crivo do Iluminismo e vive a pós-modernidade fragmentada e líquida.

A respeito da religiosidade, o cenário mostra-se bem diferente. Falou-se muito de secularização na década de 60. Um dos livros famosos daquela época foi escrito pelo bispo anglicano John A.T. Robinson: Honest to God [Um Deus diferente. Lisboa: Morais, 1967]. Vendeu milhões de exemplares em poucos meses. Ele defendia a secularização em sentido amplo a afetar indistintamente a religião, a religiosidade e a fé. No entanto, acontece nas últimas décadas verdadeira explosão do fenômeno religioso. Jovens trazem cruzes no peito, usam sinais religiosos, frequentam novos ritos como Santo Daime, União do Vegetal e outros mais. Buscam algum guru. Praticam meditação transcendental, yoga e coisas 
semelhantes de cunho religioso. Vinculados a alguma religião? Não necessariamente. Não interessa de que religião vêm as práticas e ritos. Eles valem por eles mesmos. Portanto, a religiosidade com autonomia em face da religião. No mundo católico, as TVs católicas com programas, as celebrações de padres artistas atraem multidões. A própria Internet se transforma em fonte de experiências religiosas. Então a secularização não está a afetar, antes a potencializar a religiosidade, mas sem nenhum controle da Religião institucional. Tudo depende do gosto das pessoas. Absorvem as expressões religiosas que as satisfazem e que lhes respondem o sentimento. Isso tende a crescer. A religiosidade se constitui tema interessante de pesquisa no mundo da Teologia e das Ciências da Religião.

Já bem diferente significa refletir sobre o duplo fenômeno do decréscimo da força da Religião e do aumento da religiosidade à luz da fé cristã.

A fé, no sentido profundo, pode prescindir das conjunturas da religião e da religiosidade. Para o cristão, Jesus serve de exemplo e norma. Ele morre na cruz sem religião e sem nenhuma religiosidade, Sem religião, porque o Sumo Sacerdote o chamou de blasfemo e rasgou a veste. Sem religiosidade, porque mergulhou em noite escura: "Meu Deus, por que me abandonaste”? E no Horto já tinha rezado para que Deus lhe afastasse o cálice.

A fé cristã se apoia na acolhida da Palavra de Deus, na conversão que se manifesta e se comprova na prática da justiça, do amor ao irmão, especialmente aos pobres. Tal prática de justiça, de compromisso se faz até possível fora de toda religião e fé explícita. K. Rahner chamou a essa pessoa de “cristão anônimo". Ele tem fé, sem o nome e sem explicitá-la. Caracteriza fundamentalmente a fé, viver a relação com o Transcendente pela saída de si no compromisso com o outro na justiça, no serviço, no trabalho. Não precisa necessariamente de religiosidade, embora ela ajude. Não precisa de religião, ainda que também ela sirva muito para não se viver na solidão. A religiosidade e a fé podem ser vividas em certos momentos na solidão. Cito o exemplo de Frei Beto que quando esteve preso quatro 
anos, não podia frequentar nenhuma comunidade católica. Mas esses anos não lhe abalaram a fé, nem o impediram de cumprir certas práticas religiosas. Nesse sentido, a fé consegue resistir em situações limites. Houve missionários que habitaram em tribos indígenas ou que peregrinaram por regiões inóspitas a viver praticamente só da fé, sem real contacto com a religião ou até com práticas religiosas comunitárias.

A fé os animava naquele tipo de vida. Situação exigente para a fé. Portanto, ela consegue ser vivida em qualquer situação. As circunstâncias secularizantes, pós-modernas não destroem a fé, como tal. Afetam, sim, a religiosidade e a religião, provocando-lhes aumento ou dificultando-as. A pessoa de fé, realmente tocada pela palavra transcendente, converte-se e se entrega, em circunstâncias favoráveis ou adversas à religiosidade e à religião. A fé atravessa ambas as situações. Tanto a religião como a religiosidade comportam-se diante da fé, como ajuda ou como tentação. Esta é a existência real do cristão. Então necessita de clareza de discernimento, para não deixar-se abalar na fé por causa de problemas de natureza religiosa ou institucional. No entanto, como nós não somos heróis, precisamos normalmente de religião e de religiosidade para viver a fé. Quanto mais e melhor articularmos as três, mais felizes nos sentiremos espiritualmente.

\section{REFERÊNCIAS}

INSTITUTO BRASILEIRO DE GEOGRAFIA E ESTATÍSTICA - IBGE. Censo Demográfico 2010: Características gerais da população, religião e pessoas com deficiência. Disponível em:

<http://www.ibge.gov.br/home/estatistica/populacao/censo2010/caracteristicas_religiao_deficien cia/default_caracteristicas_religiao_deficiencia.shtm>. Acesso em 29 jun. 2012.

LIBANIO, J. B. A religião no início do milênio. 2.ed São Paulo: Loyola, 2011. p. 87-110. 